\title{
The scientific and poetic creativity: knowledge in the culture
}

\author{
Julia Morkina ${ }^{1, *}$ \\ ${ }^{1}$ Institute of Philosophy, Russian Academy of Sciences, 12/1 Goncharnaya Str., Moscow, 109240, \\ Russian Federation
}

\begin{abstract}
This article describes the role of apperception and imagination (scientific and poetic) in scientific and poetic creativity in order to compare with each other. It demonstrates the importance of imagination for scientific creativity and highlights typological features of ideal objects (according to V.S. Stepin) that are common to scientific ideal objects and poetic images. The article discusses the concept of scientific and poetic meaningfulness and scientific and poetic meanings. According to the definition of N.M. Smirnova creativity is understood as the process of creation of new cultural meanings. The scientific imagination is analyzed as a necessary factor of scientific activity. The role of imagination in the apperception of the results of scientific and poetic creativity is demonstrated. It's shown that in term of phenomenology, human culture appears as the horizon where the meanings circulate as ideal objects of culture. Special attention is paid to the concepts of intersubjectivity of scientific and poetic contents. The reasons and the sources of special reliability of scientific and poetic knowledge are presented. Poetic creativity is considered as a kind of spiritual activity that has cognitive meaning. It's demonstrated that poetic creativity as well as scientific one has its own object and subject. From this perspective the analysis of poetic seems heuristic for theory of knowledge.
\end{abstract}

\section{Introduction}

Creativity is the word that have recently become relevant in philosophy. Such a term as creativity requires a philosophical definition. N.M. Smirnova proposes to define creativity as the creation of new cultural meanings in order to analyze human creativity that is important for the culture [1]. In this regard the concepts of the culture and meaning come to the fore.

In the research of the concept of meaning N.M. Smirnova shows that being one of the central concept of non-classical rationality, the concept of meaning maintains the high level of contextual polysemy, situational certainty, "theory-dependency" [1]. The meaning is considered as a special reflexive unit that relates to the state of consciousness and participates in comprehension of reality (the external and the inner ones). According to this definition the concept of meaning gets epistemological significance.

In this article we approach to our goal of creating an epistemology of the poetic by analogy with both classical and non-classical epistemologies, that research science.

\footnotetext{
*Corresponding author: alievakm@mail.ru
} 
We gain it conducting epistemological analysis of poetic creativity.

There is a high interest in cognitive sciences in modern philosophical discourse. That's why it is relevant to consider the cognitive aspect of poetic creativity, using the data of both the philosophical theory of knowledge and modern cognitive sciences in the interdisciplinary research.

Here we will use the term "apperception". Recall that in the modern philosophy apperception is conscious perception of an object. This perception depends on the previous experience, accumulated knowledge and impressions. We will also use the term "scientific imagination" which is important for conceptualization of scientific activity.

In this article we want to emphasize both the role of imagination in science as a cognitive human activity and the role of the idealization in poesy as an activity with epistemological aspect.

The special attention is payed to the concepts of the culture, meaning, scientific and poetic meaningfulness, scientific imagination, cognitive aspect of poetic creativity, intersubjectivity of scientific and poetic contents, reliability of knowledge, scientific and poetic knowledge.

If creativity is defined as the creation of new cultural meanings, the concept of meaning and meaningfulness need to be considered along with the concept of the culture. Meaning is the essence of phenomenon in the broad context of reality, inexhaustible totality (in contrast to the exhaustible meanings) of all the mental (conscious) cognitive processes associated with meaningful word or intentional object. It is also an internal logical content comprehended by the mind.

In this article we will refer to the theories of such thinkers as A.A. Potebnya and Y.M. Lotman, who analyzed the phenomenon of poetry in detail.

Some researchers refer to the works of the Russian linguist, literary scholar, philosopher A.A. Potebnya (1835-1891). I.E. Karpenko analyzes the Potebnya's doctrine of the inner form of the word and the linguo-poetic phenomenon of ornamental prose [2]. N.F. Sotsenko analyzes the refraction of some ideas of A.A. Potebnya in the modern theory of intertextuality. [3] Besides in the article "Language and poetics: analysis of the conceptions of A.A. Potebnya's followers" [4] I analyze some of his ideas that are relevant for the theory of knowledge. A.D. Vasiliev and S.P. Vasilieva explicate current trends in the development of modern sociolinguistics [5] and analyze the works of A.A. Potebnya and Y.M. Lotman. In Ukraine and Russia A.A. Potebnya is the first great theorist of linguistics who reflected on scientific and poetic knowledge.

The works of the Soviet and Russian literary scholar, culturologist and semiotician Y.M. Lotman (1922-1993) are analyzed by V.T. Faritov who explores phenomena of border and transgression in Yuri Lotman's research [6] and by L.I. Mikriukova [7], and by M. Konstantinov who analyzes communication act in the art by Y.M. Lotman [8].

V.S. Stepin whose works are analyzed by N.M. Smirnova introduces the concept of ideal objects of science $[9,10]$ N.M. Smirnova explores in detail the ontological status of sociocultural entities and Socio-humanitarian knowledge [11, 12]. She also analyzes the concept of meaning as the basic concept of phenomenology and hermeneutics. And the separate article is devoted to the concept of imagination [13].

J.S. Morkina in her works analyzes the views of social epistemologists D. Bloor and A. Goldman. The example of such a work is "Modeling in the research of discourse of scientific knowledge (social epistemology as non-classical one)" [14]. Irina V. Chernikova a, Daria V. Chernikova b, mention in their article both D. Bloor and A. Goldman [15]. 


\section{Materials and methods}

We create a special epistemology of the poetic by analogy with classical epistemology, which deals with the analysis of human scientific activity with non-classical epistemologies, which also study science. We will consider poetic creativity in terms of epistemology. There is an interest in cognitive sciences in the modern philosophical world, therefore it is relevant to consider the cognitive aspect of poetic creativity, using the data of both the philosophical theory of knowledge and modern cognitive sciences and psychology, while conducting interdisciplinary research.

The current state of philosophy is characterized by a growing interest in the problem of human creativity. These issues are also effect epistemology. And there are raised questions of scientific creativity and the role of creativity in cognition. In relation to the abovementioned, it seems relevant to study the cognitive basis of poetic creativity as a particular case of human creativity in general, and also as a completely special human creative activity. Epistemology of poetic creativity is still poorly developed.

We will pay attention to the concept of meaning (in general, scientific and poetic meanings).

The object of research is poetic creativity and in terms of epistemology its result is poetic works.

The subject of research is epistemological aspects of poetic creativity as a special human activity with a cognitive component.

The poetry plays a special epistemological role thanks to the special means: metaphors, imagination and memory, poetic images and lyrical emotions, a shift in meanings (insight) and the plurality of the poetic worlds. All this creates a special poetic reality that can be cognized, investigated by epistemological methods. The poetic reality research methodology needs to be developed. First of all, it's necessary to elaborate the concepts for epistemological analysis.

"Meaning"- concept is highlighted when creativity is defined as the creation of new cultural meanings (N.M. Smirnova). In this regard we will consider the concepts of scientific and poetic meaningfulness.

In the previous works the concept of meaning was considered as a reflexive unit that exists in the stream of consciousness. Edmund Husserl (as well as William James) defined consciousness as a continuous succession of experiences. Such experiences become meanings in reflection. Meaning is reflexive. It exists as a "concentration of reflexive understanding". Perception of consciousness that is accompanied by meaning can be called meaningfulness.

In term of phenomenology human culture is the horizon in which meanings circulate as ideal objects of the culture.

We will also focus on the concept of scientific imagination. Scientific imagination will be considered as a necessary element of scientific activity. Necessary conditions for the application of any scientific method (observation, experiment, modeling) are apperception of scientific objects and scientific imagination. Apperception of an object of experiment by a subject is necessary for planning the experiment and interpreting its results. It's also necessary for observation and modeling. Apperception and scientific imagination are important for construction of a scientific theory. It's necessary to have a certain representation of an object during all the scientific actions that are analyzed by the great Russian researcher V.S. Stepin.

We will highlight cognitive dimension of the poetic, using the analysis of the famous Russian and Ukrainian linguist, literary scholar, philosopher of XIX century A.A. Potebnya and his followers. Due to the philosopher's interest in epistemology and creative sciences it seems relevant to refer to Potebnya's works in which he analyzed similarities and differences 
of science and poesy as a creative human activity. We can compare the use of scientific and poetic imaginations if we accept that the poetic as a form of human activity has a cognitive aspect and that it is possible to highlight object and subject of poetic investigation (the analogy of scientific investigation). The ideal objects of science, its theories and the scientific picture of the world are formed as phenomena of the scientist's consciousness, and scientific creativity is impossible without scientific imagination. And the "ideal objects" of poetry (poetic images) are also formed with the help of imagination.

We will pay attention to the concept of intersubjectivity of scientific and poetic contents as well. Intersubjectivity of meanings in the culture is one of the essential characteristics of poetic and scientific meaningfulness. We will prove that the meanings in all spheres of the culture (scientific, artistic, religious, philosophical, everyday) circulate in its horizons. Meanings arise in a consciousness as subjective ones, then during communication they become intersubjective and widely used in society.

We will prove that meanings are social because they are formed from other meanings which arise in society and then being interiorized. Any meanings circulating in society are alternately subjected to interiorization and exteriorization. It's transformed both on the way from a common culture to individual consciousness and during generation of new meanings (from consciousness to collective spheres).

We will evaluate the reliability of scientific and poetic knowledge on the basis of the works of A. Goldman, D. Bloor and Y.M. Lotman.

In this article we use the methods of Phenomenology and the other philosophical disciplines, in particular, methods of classical and non-classical epistemology. Therefore, our research is interdisciplinary.

\section{Result}

\subsection{Scientific and poetic meaningfulness}

Objectification of the culture consists of meanings, which are subdivided according to the spheres of cultural manifestation into scientific, artistic, religious, philosophical, the meanings of everyday life, of the "life-world" (E. Husserl), etc.

Scientific meanings create the meaningfulness of scientific phenomena, such as ideal objects of science, the scientific picture of the world. They make possible the usage of scientific methods such as observation, experiment, modeling.

L.A. Markova introduces another criterion of scientific character that differs from the ones in theory of knowledge. According to her views criterion of scientific character can be found in the special meaningfulness (in "scientific meaningfulness"). We consider such a view to be quite heuristic, since the main role here plays scientific meaning. L.A. Markova also explores modern theoretical constructions related to the analysis of science [16]. Usually scientific meanings circulate in the part of the culture that is created by the scientific community. From this point of view, scientific meanings can be subdivided into "advanced", "routine" (T. Kuhn) and the ones that "became a part of everyday life". Advanced meanings are used in scientific hypotheses which are not fully proven and put forward by members of scientific community. This sphere of science is clear only for narrow specialists. There are scientific disputes that can lead to a "paradigm shift" (T. Kuhn). Routine meanings are related to "normal science" (according to T. Kuhn) and accompany "puzzle solving", but at the same time they are unclear to non-professionals. There is also a sphere of scientific meanings that have "become a part of everyday life". These meanings were originally formed as advanced ones, then they are routine and finally they became a part of everyday life for many members of the culture. For example, the concepts of the Solar System structure, electric current, 
corpuscular-wave nature of light etc. But even for simple reception of these scientific meanings it's necessary to have at least compulsory education. These meanings provide link between the sphere of scientific, cultural and everyday life, which enriches with meanings the other spheres (art, religion, philosophy).

Creativity as the creation of new cultural meanings leads to the transformation of the entire cultural horizon. Even a scientific hypothesis that hasn't managed to become an intersubjective one transforms human world.

Now consider poetic meanings as a particular case of artistic meanings. A.A. Potebnya considered natural language as a phenomenon of manifestation of poetic meaning. Every newly created word of natural language was considered as an elementary poetic unit. Even more so the author's poetic works (poems) are difficult for the perception of consciousness.

And we will consider poem as a complex ideal system of poetic meanings. This system is ideal as well as complex systems of scientific meanings, such as ideal objects of science and the scientific picture of the world. The ideality of these systems of meanings lies in their ontology (existence in consciousness and for consciousness). Ideal objects of science represent (as well as a poetic image) an intentional object of consciousness. A poetic work also exists in the cultural horizon and transforms it.

What is the cultural horizon in which circulate both newly created and existing meanings?

Gerhard Vollmer introduced the concept of mesocosm in evolutionary epistemology. In his view mesocosm is a world of medium speeds and dimensions, to which human being is evolutionarily adapted. According to G. Vollmer, mesocosm is a cognitive niche of a person, it's a world in which he lives and which he can explore. He considers mesocosm to be the world of medium dimensions: the world of medium distances, times, weights, temperatures, a world of low speeds, accelerations, forces, and the world of moderate complexity. According to it were created our cognitive structures. They were matched to it and they justified their reliability. The concept of mesocosm is also analyzed by H.N. Knyazeva [17].

But this concept seems insufficient when we try to use it in the analysis of human culture using phenomenological methods. The concept of mesocosm doesn't represent the ideal component of human culture. It cannot be used for conceptualization of transformations and configuration changes of the human world that take place when creating new cultural meanings. The concept of mesokosm represents only biological evolution (it also has a cognitive aspect). But this term doesn't conceptualize the development of cultural horizons. Core topic of the human world is meaningfulness. Cultural horizon, all the ideal international objects of human consciousness, all complex ideal systems of science, art, religion, philosophy, all of them consist of meanings. That's why we use the concept of "the human world" that represents all the transformations of cultural horizon.

So, during the cognitive process the meaningful part of the world constantly transforms. Along with the development and changes of the culture (art, science, religion, philosophy, everyday life) the human world undergoes transformation and configuration changes. The human world includes not only "natural" part (stars and planets, plants and animals) but also artefacts of the culture and their inherent meanings: scientific concepts and theories, works of art, etc.

Poetic "ideal objects" (poetic images) are also ideal as they exist in consciousness. Many typological features of ideal objects of science are inherent in poetic images. They also constitute certain abstractions and complex phenomena in the stream of consciousness. Imagination plays an important role both for their constitution and for scientific ideal objects. 


\subsection{The scientific imagination is analyzed as a necessary factor of scientific activity}

Observation as a scientific method is accompanied by a certain perception of the observed object. But simple perception is not enough. The observing scientist keeps in mind, apperpts the object in a certain way and also knows what he wants to achieve by this observation, what scientific hypothesis is being tested. When producing an experiment, scientific imagination is necessary at all its stages. While planning an experiment, choosing an object and a factor that will influence the object in the experiment, and trying to take into account the other external factors affecting the object, the scientist speculatively applies a testable hypothesis to the object and imagines the estimated result. The same we can observe when interpreting the results of an experiment. These results are interpreted by scientists as positive or negative depending on testable hypothesis. This hypothesis is either confirmed or not confirmed by the experiment. It may be consistent or not with the estimated results. When modelling the object of research, a scientist applies scientific imagination and analyzes the initial conditions of the model, the way of model functioning, conclusions and their conformity with the theory.

We can say the same about the ideal objects of science. V.S. Stepin divides ideal objects in physics into theoretical and empirical. He refers a point, a straight line (geometry), a material point (mechanics), an ideal gas, an absolutely blackbody (physics), ideal solution (chemistry) to theoretical ideal objects. He describes empirical ideal objects as abstractions that have the signs of real objects of experience.

Many objects of our world (stones, planets, a current-carrying wire, etc.) exist in the consciousness of a scientist as empirical ideal objects. During scientific assessments, there is an abstraction from some of the characteristics of these objects and focusing on the others, which become the subject of scientific manipulation.

Scientific imagination is used to create both theoretical and ideal objects of science. Scientific imagination is the constituting of these objects in the mind of a scientist with the creation of new scientific meanings. Theoretical and empirical ideal objects exist in the minds of scientists. The creation of an empirical ideal object as a subject of science implies thinking about the significant and insignificant factors that influence the object of research. Empirical ideal objects are depending on theory. But it is impossible to imagine not speculative scientific theory that would not be the result of scientific imagination. When creating a scientific theory, scientific imagination operates as the factor that defines this theory and its apperception by members of the scientific community.

Now we will proceed to consider the poetic.

\subsection{The cognitive dimension of poetic}

A.A. Potebnya compared poesy to science when he described the cognitive aspect of poetic. A separate word of a natural language for A.A. Potebnya is a poetic unit that helps in the cognition of a newly named object. It takes place when the most essential characteristic is highlighted and when there is a metaphorical transfer of knowledge about this characteristic from the already known object to a newly cognized one.

A.A. Potebnya also considers more complex poetic formations, such as author's fables or poems and works of folklore, in term of epistemology. According to his view, poetic work "answers the question" of a reader. Moreover, it's probably that the author didn't have this question in mind. A poem in society has its own intersubjective "life" and its own "biography" (A. Gornfeld is a follower of Potebnya). Creativity is the creation of cultural meanings that circulate in society. They are intersubjective. And A.A. Potebnya emphasizes that language as a form of poesy can exist only in society. 
According to A.A. Potebnya, poetic activity helps human thinking, accelerating it and helping to "embrace" the world, that is infinite in space and time ("in width" and "in depth").

The speed of apperception of such a world is also increased by poetry with its ability to place life phenomena in an image. A.A. Potebnya also writes that a poetic image can be called ideal if the representation of the word is ideal. Idealization as the creation of a poetic image consists in highlighting from the main complex of perceptions, in uniting of certain characteristics and in absence of others. This is also a distraction that differs from scientific only in specific characteristics. According to A.A. Potebnya, an allegory is figure with cognitive meaning.

It should be reminded that a word of natural language contains three elements, one of which is a representation. Representation of a word is its closest etymological meaning. The example is the Russian word "защита" (protection). The closest etymological meaning is "за щитом" ("behind the shield"). The representation of the word has metaphorical meaning. But at the same time it has cognitive one, since it helps to cognize the object.

\subsection{Intersubjectivity in scientific and poetic contents}

Intersubjectivity is a critical factor for scientific meanings that form such complex ideal systems as scientific hypothesis, scientific ideal objects, the scientific picture of the world. Actually, reproducibility and intersubjectivity of the results of scientific activity are the criteria of scientific character. They underlie scientific reliability. The results of the application of such scientific methods as observation, experiment, modeling should become the property of the scientific community. No wonder T. Kuhn highlights the concept of the scientific community when creating his theory of scientific revolutions. He considers the entire change of paradigms as a social process. Considering the origins of scientific hypotheses and theories, they use the context of discovery and the context of justification. The first one often consists of inspiration and occurs in the individual consciousness of scientist. It needs the second one (the formulation of intersubjective scientific proof). Social epistemologists (for example, David Bloor) don't consider individual transformations of meanings in the consciousness to be scientific processes.

All that concerns intersubjectivity of scientific meanings. And what about artistic and poetic meanings? Socialization of the consciousness (at the level of socialization of the consciousness of adult) is necessary for their emergence in the individual consciousness. Besides in the emergence of complex poetic systems of meanings (poetic work) an important role plays the state of inspiration as a state of readiness for insight and insight itself. But a poetic work after creation is evaluated by society and it becomes the part of the culture. And its images become new cultural meanings, or otherwise complex systems of meanings. Poetic "fate" of a poetic work depends on society and the era in which it appeared and exists. But truly brilliant works of art tend to "transcend" epochs. And a reader of any time finds in them his own meanings that answer his individual questions, which the author may never have had in mind. These are the properties of scientific and artistic meanings. They have the possibility (however, it's not always realized) to exist inter subjectively and to transform the horizon of the culture.

\subsection{Reliability of scientific and artistic knowledge}

Theorists of science, starting with classical epistemologists and ending with theorists of nonclassical epistemologies (such as social epistemology and evolutionary epistemology) have discussed the problem of reliability of scientific knowledge. In fact, the issue of reliability underlies the problem of demarcation science from non-science. This demarcation was based 
by epistemologists in the validity of scientific theories, and the criterion of falsifiability (K. Popper).

L.A. Markova proposes scientific meaningfulness as a new criterion to distinguish science from non-science. The creation of scientific meanings helps to identify a true scientist. In social epistemology of D. Bloor social division make knowledge more reliable. Intersubjectivity is also a criterion for scientific character. It gives to knowledge a sense of reliability.

The main value for D. Bloor is "social" and the reliability of knowledge is provided by its social nature. At the same time the main value for the social epistemologist A. Goldman is the concept of truth. His project is based on it. He defends this concept against the attacks of postmodernists, but not always being consistent. Absolutism and realism are inherent to this author. According to his own classification A. Goldman is related to the classic approach of social epistemology (to one in which special attention is paid to the traditional epistemic goal of development of true beliefs). The aim of the book "Knowledge in a Social World" by Goldman is to develop a framework for evaluation of social practices in terms of their impact on the truth characteristics of beliefs.

A. Goldman defines social epistemology as a discipline that evaluates social practices in terms of their truth value.

There is a "veritistic" (from Latin "veritas", Goldman's term) evaluation of social practices. It's based on the fact that a belief has a certain value (V-value) which depends on closeness of the belief to reality. In this regard, "veritistic" evaluation (V-evaluation) of social practice becomes possible. It's based on its valuability in term of true beliefs (knowledge).

A. Goldman clearly distinguishes between justificability of a statement and its truth. In his opinion the concepts of obviousness and justificability are insufficient to say about the truth of the statement. In Goldman's definition of the V-value ("veritistic", true value) of social practices, there is no value in the fact of justificability. Whether a statement is based on evidence or not, it evaluates the truth of belief. According to A. Goldman justificability is considered only as a tool for achieving truth although the justificability of beliefs is considered to be epistemic value. There we may remember that according the view of $\mathrm{K}$. Popper it becomes difficult to determine the reliability of scientific knowledge because we can have true beliefs but we may not know that it is true.

F.F. Schmitt criticizes Goldman and introduces his own concept of J-value (from English “justification"). It can be defined similarly to Goldman's V-value as the degree in which practice increases the validity of judgments, and the sense of their reliability.

A. Goldman denies that the purpose of argumentation is not only true but also valid belief. Thus, for him science-based knowledge doesn't mean reliable one.

A. Goldman calls his theory of truth "descriptive-success" (DS). It builds on the usage of the word "truth" in natural English, indicating the connotation of the word with words expressing success.

Goldman's theory differs from the other correspondence theories of truth. It implies existence of "truth makers", (it means any kind of world essence, that make statements about reality true).

The usual "candidate" in "truth makers" is fact. But it raises the problem of isomorphism of judgements and facts (L. Wittgenstein, B. Russell, W. Quine).

A. Goldman avoids this problem by arguing that correspondence theory should not be full of facts. He just formulates the concept of "truth makers" as a part of reality (so it has broad meaning). Conformity with the theory of reality is not considered by A. Goldman as isomorphic ("one-one").

A. Goldman interlinks the concepts of truth and knowledge using the doctrine of reliabilism (reliability theory) that he adopted. It states that belief can be formed by truthconducive or non-truth-conducive processes. The former ones are more likely to be true than 
the latter ones. So, belief presents in such extra-linguistic and non-conventional factors as perception and memory. The usual view of reliabilism is that our attitude to truth must be considered in terms of how our cognitive processes bring us closer to the goal of maximizing true beliefs. A. Goldman has the same one.

The reality of mental states is questionable for D. Bloor. They are considered as an epiphenomenon of human social life, being at the same time "highlighted" in the model of speaking and actions. And for A. Goldman the presence of certain and determinable mental states of an individual is an axiom, that is not subject to proof and that the underlies model of action and evaluation of social practices. Thus, according to A. Goldman, scientific reliability is provided by internal processes in consciousness (Goldman's "mentalism").

Knowledge is the first "mentalistic" concept to be included in Goldman's model. He understands total knowledge as the sum of the knowledge of separate individuals, and the knowledge of an individual as his definite internal state. So, Goldman's concept of knowledge is a mentalistic concept. D. Bloor considers concept of knowledge to be an institutionalized conviction (statements, since conviction is also a mentalistic concept, and mentalism is not recognized by D. Bloor, who builds a model of the social construction of so-called " inner reality"). Being a mentalist, A. Goldman is also an individualist.

Table 1. Comparison of the cognitive characteristics of the ideal object of science and the poetic image.

\begin{tabular}{|c|c|c|c|c|c|c|c|}
\hline 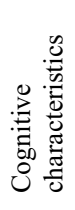 & 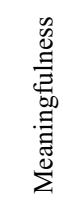 & 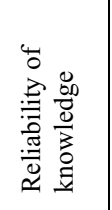 & 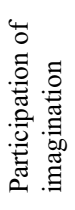 & Participation of apperception & 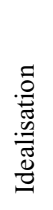 & 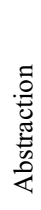 & 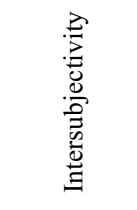 \\
\hline 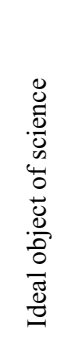 & 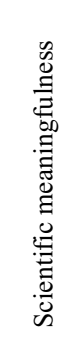 & 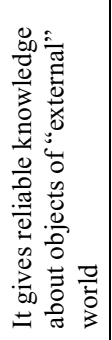 & 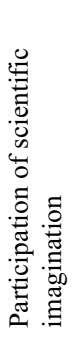 & $\begin{array}{l}\text { 1) apperception of existing } \\
\text { scientific hypothesis and } \\
\text { theories by individual } \\
\text { consciousness } \\
\text { 2) creation and apperception } \\
\text { by scientist of new scientific } \\
\text { meanings for the culture }\end{array}$ & 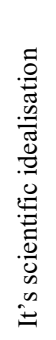 & 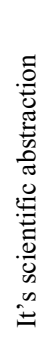 & 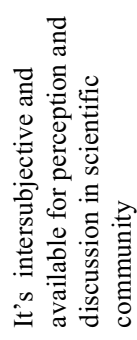 \\
\hline 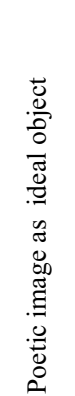 & 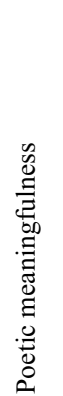 & 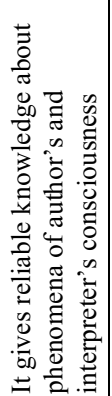 & 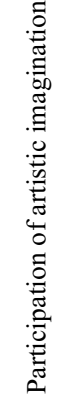 & $\begin{array}{l}\text { 1) apperception of previously } \\
\text { created poetic works by } \\
\text { individual consciousness } \\
\text { 2) creation and apperception } \\
\text { of new artistic cultural } \\
\text { meanings by authors }\end{array}$ & 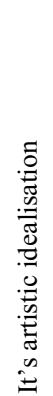 & 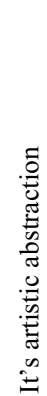 & 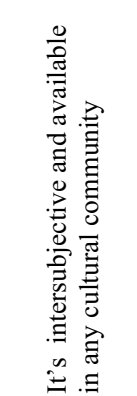 \\
\hline
\end{tabular}

But he considers himself to be a social epistemologist, since his model of scientific knowledge allows to evaluate social practices and to attribute to them the generation and maintenance of true beliefs (as well as false ones). 
A. Goldman takes the state of consciousness of individual for a unit of knowledge (and a stronghold of reliability). It means that he is confident in a true statement (statement which has "truth makers" in reality). That is why Goldman's concept of knowledge is a mentalistic concept, while D. Bloor considers a concept of knowledge as an institutionalized conviction.

All this concerns the reliability of scientific knowledge. And what about artistic and poetic knowledge? The very concept of "poetic knowledge" may be considered as controversial.

However, Y.M. Lotman also considered poetic works as complex systems. In his view, poetic speech is a structure of great complexity. It is much more complicated in relation to natural language. He also wrote that there is another problematic aspect in the correlation between the author's synthetic artistic code and the analytical code. Both of these codes represent a hierarchical structure of great complexity. The matter is complicated by the fact that one and the same text at different levels can obey different codes. For artistic communication the author's and the reader's codes must form intersecting sets of structural elements. Moreover, drawing attention to the epistemological side of poetry, Y.M. Lotman considered a poetic work as a model of the world: a work that is essentially finite as a model of an infinite world, pointing out the modelling function of both languages in general and poetic language. The secondary modelling system of the artistic type constructs its own system of denotata, which is not a copy, but a model of the world of denotata in the general linguistic sense. He considers poetic art as a language connected with a certain model of the world.

We are taking the view that, during analysis of poetic knowledge, it makes sense to consider its reliability, but not its truth.

The comparison of the ideal object of science with a poetic ideal object (poetic image) can be presented in the table 1.

\section{Discussion}

\subsection{Scientific and poetic meaningfulness}

So, we have shown that the meaningful part of the world constantly transforms in the process of its cognition, and the human world undergoes transformation and configuration change with the development and change of the culture. Ideal objects (scientific, poetic, and the ones of the other types of human spiritual activity: art, religion, philosophy, etc.) also circulate in the culture.

But scientific imagination is used to create both theoretical and ideal object of science. Scientific imagination is the constituting of these objects in the mind of a scientist with the creation of new scientific meanings. Ideal objects of science and poesy are ideal in the sense that they exist in the minds of the subjects of the culture. The use of scientific and poetic imaginations is one of the ways to operate with ideal objects in the mind. Imagination is also involved in the subject's apperception of the object of knowledge. Any scientific theory is speculative to a certain extent, and scientific imagination participates in its apperception by consciousness.

In general, the apperception of the object of cognition in science can be divided into two types:

1) the perception of scientific hypotheses and theories that exists in science and known to the scientific community by the individual consciousness and their apperception by the individual scientist's consciousness; 
2) the constitution by scientist of scientific meanings new to the culture (they not always explain reality perfectly). But, creating these meanings a scientist seeks to an ideal description, a scientific explanation of reality, an ideal apperception of the object under study.

We distinguish two types of apperception in science and the similar ones can be distinguished while analyzing poetic creativity:

1) perception and apperception of poetic works (that has already been created by its author and socialized) by individual consciousness.

2) creative constitution of new meanings (and images) (that have special reliability as means of cognition of the world, as its model) by the subject (author) (Y.M. Lotman).

In line with the interpretation of the poetic as cognitive, we can point out the typological features that are common to the poetic image and the scientific ideal object. Both are ideal in the sense when they are constituted in the consciousness (of a scientist, author, reader). At the same time, both of them are intersubjective, they can circulate in human society, bringing their new cultural meanings. In science, these are scientific meanings created by scientists, in poesy these are poetic meanings. But both of them are used in cognition.

We have shown that the poetic image has many typological features of the ideal object of science. In addition to ideality and existence in consciousness, poetic image, just like a scientific ideal object, is a distraction. It is also abstracted from the empirical object, the knowledge of which transfers. The bird cherry described by Bella Akhmadulina is not the bird cherry in the vase that is on her table. The poet abstracts from some of its properties and highlights the other ones. In this case, these are the properties that bird cherry acquires by appercipating with the consciousness of the poet. At the same time, the poet dwells on those properties that detect important for the poet existential meanings. These meanings are new elements of the culture. They help person to cognize both the "external" world and himself.

In our work we have discussed the concept of reliability of scientific and poetic knowledge. In our research we often refer to the works of A.A. Potebnya. He analyzed the scientific and poetic activities of human being and conducted detailed comparative analysis. According to Potebnya, the elementary unit of poesy is the word of natural language. According to his views, the naming of an object or phenomenon is its poetization (but Potebnya does not use this word). And naming of the object provides the cognition of the named object. A.A. Potebnya compares poesy with science. He finds much in common in terms of idealization and typification in these spheres. The creation of ideal objects and idealized images of reality takes place in poesy and in science. Poetization of a subject facilitates and accelerates its cognition.

The poetic image created by the author has the features of the "model of the world" (Y.M. Lotman), and the lyrical hero appears as an ideal transcendental construct, a "model" of a transcendental subject. This is a current model that becomes a model of the readerinterpreter's consciousness through his co-creation with the author of the work. In terms of providing cognition of certain realities, this model has its own specifics. Namely, we can consider the reliability of poetic knowledge in terms of "answers to questions" that characterize the state of consciousness of the reader. The reader, who perceive a poetic work, receives a certain knowledge about himself, about his inner reality, "reacting" with the work created by the author. So, knowledge about the world, about the author and about oneself all this is the interpreter finds in the poetic work. The reliability of this knowledge is related to poetization as a way of cognition. It accompanies deep existential emotions that are peculiar to the subject who colonizes the world and himself through poetry. Reading and creating poems for those, who take these studies seriously, become a metaphor for the very being of the subject and open to him the depth of his soul. And this specific knowledge shows the special reliability that can be compared with the reliability of scientific knowledge. 


\section{Conclusion}

So, we have analyzed the role of the scientific imagination in scientific creativity, considered poetic creativity in term of ideal objects created in it. Those ideal objects are functioning as cultural meanings. From our point of view, comparative analysis of science and poesy in the cognitive sense should be heuristic for theory of knowledge and for analysis of human creativity in general.

We have shown that meaningfulness (scientific and poetic) can be considered as a criterion of scientific or poetic cognition that takes place in the horizon of human culture. We understand creativity (according to the definition by N.M. Smirnova) as the creation of new cultural meanings. At the same time, the meanings circulating in the culture and emerging in individual minds are intersubjective. They have the characteristics of the culture in which they exist.

As a criterion for poetic knowledge we have chosen its special reliability, first considered the problem of the reliability of scientific knowledge. Considering the question of the reliability of scientific knowledge, we paid special attention to social epistemology as one of the non-classical epistemologies. We also analyzed the "veritistic" theory of cognition by A. Goldman. Considering poetic knowledge and its reliability, we refer to A.A. Potebnya and Y.M. Lotman, who analyzed poesy as a cultural sphere in great detail. We highlight the statements about the cognitive nature of this sphere and about the cognition. We also analyze the culture in general, in which poetic and scientific creativity takes place as the creation of new cultural meanings and their systems, which then exist as intersubjective cultural phenomena.

\section{References}

1. N.M. Smirnova, The concept of meaning in hermeneutical practices, Questions of social theory. Scientific almanah. Vol. X. Man and his meanings in the context of civilization development of Russia (M.: Publishing House of the Independent Institute of Civil Society, 2018) DOI 10.30936/2227-7951-2018-10-25-37

2. I.E. Karpenko, The teachings of Potebnya on the inner form of the word and the linguo -poetic phenomenon of ornamental prose, Language and text 5, 2, 3-8 (2018) DOI: 10.17759/langt.2018050201

3. N.F. Sotsenko, The refraction some ideas A.A. Potebnya in intertextuality theory (based on material of the article "psychology of poetic and prosaic thinking), Russian philology: Bulletin of Kharkiv National Pedagogical University named after H.S. Skovoroda 4 (59) (2016) DOI: http://doi.org/10.5281/zenodo.165453

4. J.S. Morkina, Language and poetics: analysis of the conceptions of A.A. Potebnja's followers. Part I: A.A. Potebnja, V. Kharzeev, B.A. Lezin. Filosofiya Osvity, Philosophy of Education 1(24), ISSN 2309-1606, 154-173 (2019) DOI: https://doi.org/10.31874/2309-1606-2019-24-1-154-173

5. A.D. Vasiliev, S.P. Vasilieva, Current trends in the development of modern sociolinguistics, Bulletin of Krasnoyarsk State Pedagogical University named after V.P. Astafyev 44(2), 153-160 (2018) DOI: https://doi.org/https://doi.org/10.25146/19950861-2018-44-2-69

6. V.T. Faritov, Phenomena of border and transgression in Yuri Lotman's research: ontological bases of the semiotic philosophy, Bulletin of Tomsk State University 434, 77-82 (2018) DOI: 10.17223/15617793/434/9 
7. L.I. Mikriukova, Loss and compensation in literary translation, Bulletin of Tyumen State University Herald. Humanities Research. Humanitates 4, 2, 84-94 (2018) DOI: 10.21684/2411-197X-2018-4-2-84-94

8. M. Konstantinov, Communication act in the art by Y.M. Lotman, Bulletin of Kyiv National University of Culture and Arts. Series in Audiovisual Arts and Production 2(1), 67-76 (2019) DOI: 10.31866/2617-2674.2.1.2019.170873

9. N.M. Smirnova, V.I. Arshinov, F.N. Blyukher, V.G. Budanov, et al, Science and culture coevolution in S. Stepin's works, Philosophy of Science and Technology 24, 1, 7-45/3032, 2413-9084 (2019) DOI: 10.21146/2413-9084-2019-24-1-7-45

10. V.S. Stepin, N.M. Smirnova, J.V. Sineokaya, Does the methodological isomorphism between natural and social sciences exist? Philosophy journal XI 3, 150-165, 20720726 (2018) DOI 10.21146/2072-0726-2018-11-3-15-165

11. N.M. Smirnova, D.R. Schtikov, The ontological status of socio-cultural entities as an object of phenomenological critique (A. Schutz, R. Ingarden), Philosophy journal 13, 4, 89-101, 2072-0726, 2658-4883 (2020) DOI 10.21146/2072-0726-2020-13-4-89-101

12. N.M. Smirnova, Socio-humanitarian knowledge: specificity or knowledge of foreign nature? Philosophy of Science and Technology 25, 2, 7-10, 2413-9084, 2658-7297 (2020) DOI: https://doi.org/10.21146/2413-9084-2021-25-2-5-8

13. N.M. Smirnova, Imagination and Creativity: cognitive analysis, International Journal Socio-Humanitarian Review (IJSHR) 3, 12-21, 2346-8408 (2018) DOI 10.24411/23468408-2018-10002

14. J.S. Morkina, Modeling in research of discourse of scientific (social epistemology as non-classical), Philosophy Journal 1(6), 86-102 (2011)

15. I.V. Chernikovaa, D.V. Chernikova, Socio-technocratic Discourse of Technoscience, Procedia - Social and Behavioral Sciences 166, 511-515 (2015) https://doi.org/10.1016/j.sbspro.2014.12.563

16. L.A. Markova, The Humanisation of the Surrownding World and the Technisation of Humans, Epistemology Review and Reply Collective 3, 3, 49-52 (2014)

17. H. Knyazeva, The Natural Medium as Carrier of Meanings and Their Decoding by Living Beings: Biosemiotics in Action, Filosofiya Osvity. Philosophy of Education 3(2), 192-218 (2018) DOI: https://doi.org/10.31874/2309-1606-2018-23-2-192-218 